\title{
Actual application of virtual angioscopy: Is it yet to come?
}

\author{
Phillip S. Naimo, MD, Edward Buratto, MBBS, and Igor E. Konstantinov, MD, PhD, FRACS
}

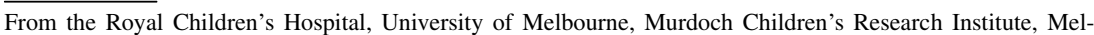 \\ bourne, Australia. \\ Disclosures: Authors have nothing to disclose with regard to commercial support. \\ Received for publication March 21, 2016; accepted for publication March 24, 2016; available ahead of print April \\ $27,2016$. \\ Address for reprints: Igor E. Konstantinov, MD, PHD, FRACS, Royal Children's Hospital Flemington Rd, Park- \\ ville, VIC 3029, Australia (E-mail: igor.konstantinov@rch.org.au). \\ J Thorac Cardiovasc Surg 2016;152:211-2 \\ $0022-5223 / \$ 36.00$ \\ Crown Copyright (c) 2016 Published by Elsevier Inc. on behalf of The American Association for Thoracic Surgery \\ http://dx.doi.org/10.1016/j.jtcvs.2016.03.052
}

An interesting article by Brothers and colleagues ${ }^{1}$ is published in the current issue of the Journal. The article describes the use of cardiac magnetic resonance imaging (MRI) for virtual angioscopy (VA) to evaluate coronary anatomy, myocardial injury, and left ventricular function in 9 children who underwent repair of the anomalous aortic origin of a coronary artery. The study demonstrates that high-quality imaging, showing the surgical view of coronary ostial anatomy and proximal coronary arteries, can be achieved by MRI in children with anomalous coronary arteries both before and after unroofing. As with advances in any technology, this MRI technique brings to clinicians not only new information but also an old question: "What to do about it?" A few comments seem appropriate to bring this important article into proper prospective.

Currently, surgical repair is recommended in all patients with an anomalous left coronary artery from (Figure 1, A and $B$ ) the right coronary sinus ${ }^{2,3}$ and in symptomatic patients with an anomalous right coronary artery from the left coronary sinus. ${ }^{2,3}$ In most cases, the stenotic orifice is unroofed (Figure 1, C). ${ }^{4,5}$ However, simple unroofing does not alter the interarterial course of the coronary artery. The latter still comes tangentially form the aorta and could be compressed between the 2 great arteries if not fully unroofed. A concept of pulmonary artery translocation has been described to prevent compression of the anomalous coronary artery. ${ }^{6}$ However, pulmonary artery translocation is unlikely to achieve any meaningful separation of the great arteries below the area of the sinotubular junction (ie, in the area where coronary compression is likely to occur). Thus, we prefer to translocate (Figure 1, $D)$ the unroofed coronary artery into its natural anatomic position. ${ }^{7}$ A slight rotation may be required to prevent kinking of the unroofed coronary artery. An intramural course of the coronary artery behind the aortic valve commissure could complicate transfer and require detachment and reattachment of the commissure. ${ }^{7}$ A low threshold in translocating the unroofed coronary artery comes from our experience in dealing with intramural coronary arteries during the arterial switch operation. ${ }^{8}$ Surgeons who perform



Origin of the coronary artery from the opposite sinus with an interarterial course.

Central Message

VA using MRI is helpful in visualization of the proximal coronary arteries in children.

See Article page 205.

the arterial switch operation would be comfortable translocating unroofed coronary arteries. Whether the unroofed coronary artery is translocated or not, a slit-like appearance of the unroofed ostium is an expected finding. It is not the shape of the unroofed coronary artery but rather its narrowing that would be of concern. A slit-like appearance may not look aesthetically pleasing, but such an appearance per se would not warrant reoperation.

Most importantly, in the hands of Brothers and colleagues, ${ }^{1}$ MRI-VA beautifully demonstrated not only the proximal anomalous coronary arising tangentially to the aorta with an elliptical, slit-like ostium in all patients, which was confirmed intraoperatively, but also the position of the ostium relative to the aortic valve commissure to determine if the ostium was juxtacommissural. This is important for surgical planning, because the aortic valve commissure may have to be taken down and reattached after unroofing and reimplantation of the anomalous coronary artery. $^{4,5}$ This has certainly been our experience with an anomalous aortic origin of a coronary artery. ${ }^{7}$ In addition to these anatomic details, the MRI technique described can be used to provide important information regarding the functional state of the myocardium, including ventricular wall motion, myocardial perfusion, and the presence of wall thinning or scar.

Of particular value, in our opinion, is postoperative assessment of the neo-ostium. Brothers and colleagues ${ }^{1}$ demonstrated that 2 of their 7 patients had narrowed neoorifices postoperatively. No reoperation was performed, because both of these patients had an anomalous right coronary artery, were asymptomatic, and had no evidence of ischemia on stress testing. The significance of the narrow neo-ostium in this situation is unknown. Current guidelines recommend that patients who have undergone repair of anomalous aortic origin of a coronary artery may return to sport activities 3 months after repair provided they have 

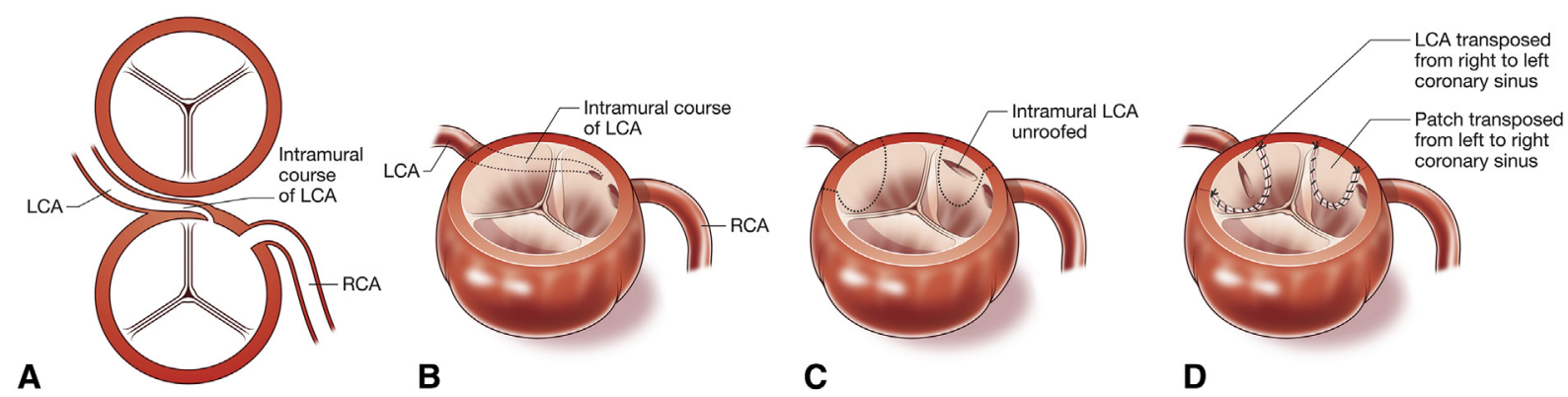

FIGURE 1. Anomalous aortic origin of the left coronary artery from the right coronary artery sinus (A and B) with a narrow origin and intramural course of the proximal interarterial portion of the coronary artery. The intramural segment of the left coronary artery is unroofed (C), and the left coronary artery is translocated to its normal anatomic position (D). A slight rotation of the translocated coronary artery may be required to prevent kinking. $L C A$, Left coronary artery; $R C A$, right coronary artery.

no evidence of ischemia on stress testing. However, a sudden death has been reported after unroofing, despite normal stress testing. ${ }^{9}$ The combination of anatomic information on the ostium size, shape, and location, as well as functional information on wall motion and myocardial perfusion, which can be provided by MRI-VA, would be particularly valuable in these patients.

Furthermore, it is possible that some patients have ongoing residual narrowing of the anomalous coronary arteries after unroofing or reimplantation, but this narrowing is undetected with current postoperative evaluation, and this concern is not limited to patients with anomalous aortic origin of a coronary artery. Accurate knowledge of the coronary anatomy also would be useful in patients with transposition of the great arteries, particularly when additional complexity has been encountered in children with intramural coronary arteries. ${ }^{8}$ Clearly, MRI-VA would have an application in this setting, both preoperatively for surgical planning and postoperatively for assessing the anatomy of the reconstructed coronary arteries. Patients with anomalous origin of the left coronary artery from the pulmonary artery require coronary translocation ${ }^{10}$ and also likely would benefit from postoperative evaluation of the reimplanted coronary artery. Noninvasive MRI-VA assessment would be beneficial to assess the long-term patency, particularly because some patients with good collaterals may remain asymptomatic and have a normal stress test result, despite significant ostial narrowing of the reimplanted coronary artery.

The application of this technique will require skills, sufficient caseload to maintain expertise, and time because it is dependent on accurate gating for image fidelity. ${ }^{1}$ The article by Brothers and colleagues ${ }^{1}$ is a remarkable and important step forward. It is safe to say that MRI-VA is here to stay. The actual application of this virtual modality will need further refinement to be used routinely.

\section{References}

1. Brothers JA, Kim TS, Fogel MA, Whitehead KK, Morrison TM, Paridon SM, et al. Cardiac magnetic resonance imaging characterizes stenosis, perfusion, and fibrosis preoperatively and postoperatively in children with anomalous coronary arteries. J Thorac Cardiovasc Surg. 2016;152:205-10.

2. Mainwaring RD, Reddy VM, Reinhartz O, Petrossian E, MacDonald M, Nasirov T, et al. Anomalous aortic origin of a coronary artery: medium-term results after surgical repair in 50 patients. Ann Thorac Surg. 2011;92:691-7.

3. Sharma V, Burkhart HM, Dearani JA, Suri RM, Daly RC, Park SJ, et al. Surgical unroofing of anomalous aortic origin of a coronary artery: a single-center experience. Ann Thorac Surg. 2014;98:941-6.

4. Dekel H, Hickey EJ, Wallen J, Caldarone CA. Repair of anomalous aortic origin of coronary arteries with combined unroofing and unflooring technique. J Thorac Cardiovasc Surg. 2015;150:422-4.

5. Frommelt PC, Sheridan DC, Berger S, Frommelt MA, Tweddell JS. Ten-year experience with surgical unroofing of anomalous aortic origin of a coronary artery from the opposite sinus with an interarterial course. J Thorac Cardiovasc Surg. 2011;142:1046-51.

6. Gulati R, Reddy VM, Culbertson C, Helton G, Suleman S, Reinhartz O, et al. Surgical management of coronary artery arising from the wrong coronary sinus, using standard and novel approaches. J Thorac Cardiovasc Surg. 2007;134: 1171-8.

7. Jadhav M, Pflaumer A, Naimo PS, Konstantinov IE. Anomalous aortic origin of the left coronary artery from the right coronary sinus: diagnosis and surgical repair of intramural retrovalvular coronary artery. Ann Thorac Surg. 2015;100: 2357-9.

8. Fricke TA, Bulstra AE, Naimo PS, Bullock A, Robertson T, d'Udekem Y, et al. Excellent long-term outcomes of the arterial switch operation in patients with intramural coronary arteries. Ann Thorac Surg. 2016;101:725-9.

9. Nguyen AL, Haas F, Evens J, Breur JM. Sudden cardiac death after repair of anomalous origin of left coronary artery from right sinus of Valsalva with an interarterial course: case report and review of the literature. Neth Heart J. 2012;20: 463-71.

10. Naimo PS, Fricke TA, d'Udekem Y, Cochrane AD, Bullock A, Robertson T, et al. Surgical intervention for anomalous origin of left coronary artery from the pulmonary artery in children: a long-term follow-up. Ann Thorac Surg. February 18, 2016 [Epub ahead of print]. 